\title{
Comparison of Induced Deflection and Forces in Piles Adjacent to Tunnelling and Deep Excavation in 2D and 3D Problems
}

\author{
Ong Yin Hoe ${ }^{1, *}$ and Hisham Mohamad ${ }^{2}$ \\ ${ }^{1}$ Department of Civil and Environmental Engineering, Universiti Teknologi PETRONAS, Seri Iskandar, Malaysia
}

\begin{abstract}
There is a trend in Malaysia and Singapore, engineers tend to model the effect of TBM tunneling or deep excavation to the adjacent piles in 2D model. In the 2D model, the pile is modelled using embedded row pile element which is a 1-D element. The user is allowed to input the pile spacing in out-of-plane direction. This gives an impression to engineers the embedded pile row element is able to model the pile which virtually is a 3D problem. It is reported by Sluis (2014) that the application of embedded pile row element is limited to $8 \mathrm{D}$ of pile length. It is also reported that the $2 \mathrm{D}$ model overestimates the axial load in pile and the shear force and bending moment at pile top and it is not realistic in comparison to 3D model. In this paper, the centrifuge results of single pile and 6-pile group - tunneling problem carried out in NUS (National University of Singapore) are back-analysed with Midas GTS 3D and a 2D program. In a separate case study, pile groups adjacent to a deep excavation is modelled by $3 \mathrm{D}$ and $2 \mathrm{D}$ program. This paper compares the deflection and forces in piles in 2D and 3D models.
\end{abstract}

\section{Introduction}

There are more and more numerical analyses were carried out for development fall within the first and second reserve of MRT line in recent years in Malaysia, especially in Klang Valley, starting from year 2010 as part of the requirement of submission to MRT Corp. for the developer to get approval of development. However, engineers in Malaysia and Singapore are taking the advantage of $2 \mathrm{D}$ analysis in analysing a truly $3 \mathrm{D}$ problem particularly in pile-tunnel interaction and the effect of deep excavation to adjacent piles. Therefore, it is necessary to investigate the ability of the $2 \mathrm{D}$ analysis in a real $3 \mathrm{D}$ problem. It is particularly interesting to test the embedded pile rows element in $2 \mathrm{D}$ analysis in which engineers are in font of using it to model piles in $2 \mathrm{D}$ analysis.

\subsection{Background of embedded pile row}

Embedded pile row element was introduced in 2014 by Sluis et.al and it is available in Plaxis AE onwards as to overcome the drawback of modelling the pile using beam element and anchor node in 2D analysis. Description and formulation of the embedded pile row can be found in Sluis (2014), Kwaak (2015) \& Plaxis (2017). There are two important figures proposed by Sluis (2014). Figure 1 shows the concept of the embedded pile row where the imaginary nodes with springs are created to model the pile. The imaginary node is not the same node as element node. The nodes are then connected to the soil element by the built-in interface element. The other more important point from Sluis (2014) is that the embedded pile element is only suitable for pile length of up to $8 \mathrm{D}$, where $\mathrm{D}$ is the diameter of the pile.

\footnotetext{
${ }^{*}$ Corresponding author: yin_16000482@utp.edu.my
} 


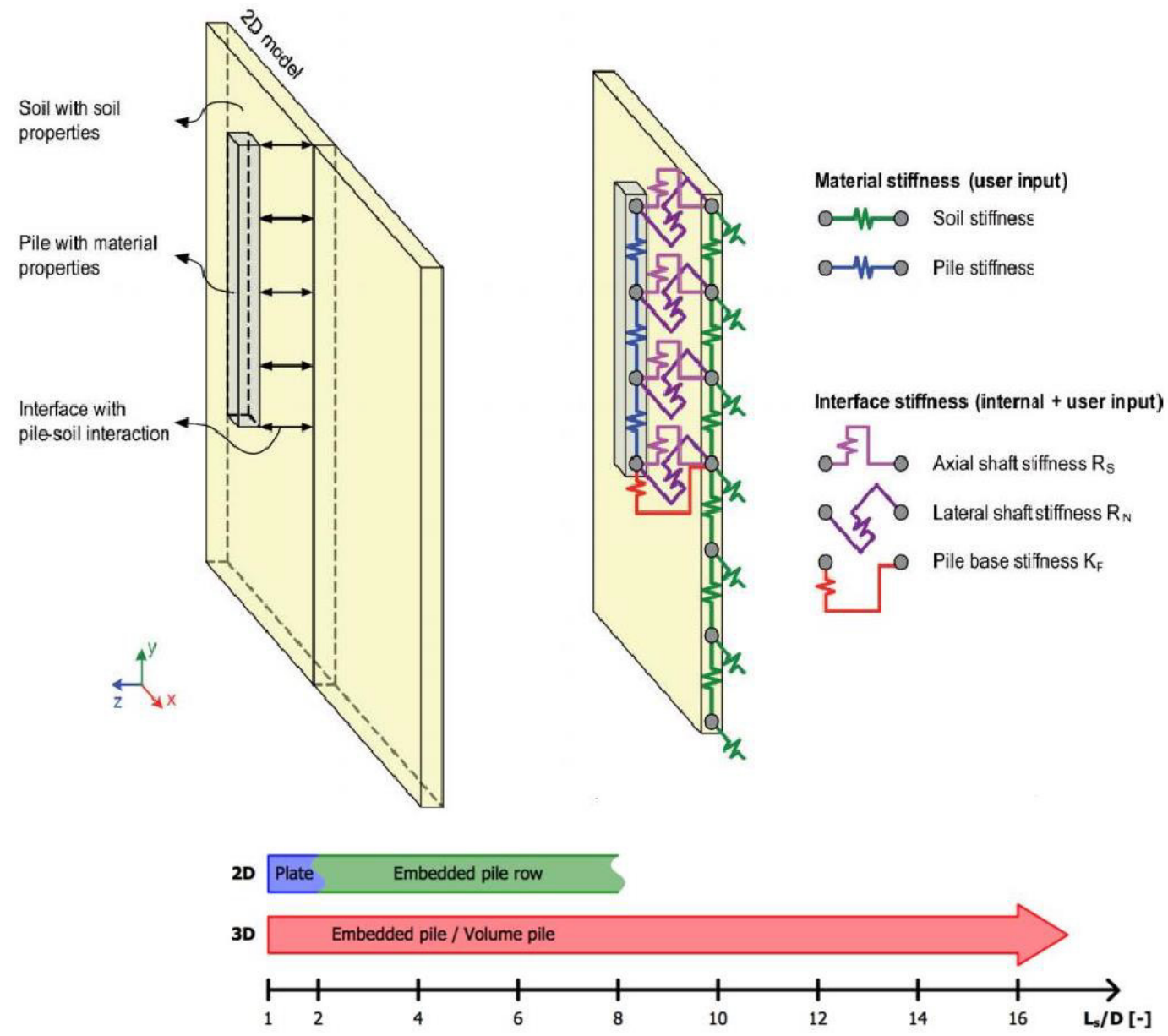

Fig. 1. Principle of embedded pile row in Plaxis 2D (after Sluis, 2014)

\section{The effect of tunnelling to adjacent piles}

In order to investigate the behaviour of the embedded pile row in pile-tunneling problem, the test results from centrifuge carried in NUS by Ong (2009) was modelled. Two cases are back-analysed using Plaxis 2D and Midas GTS NX 2017.
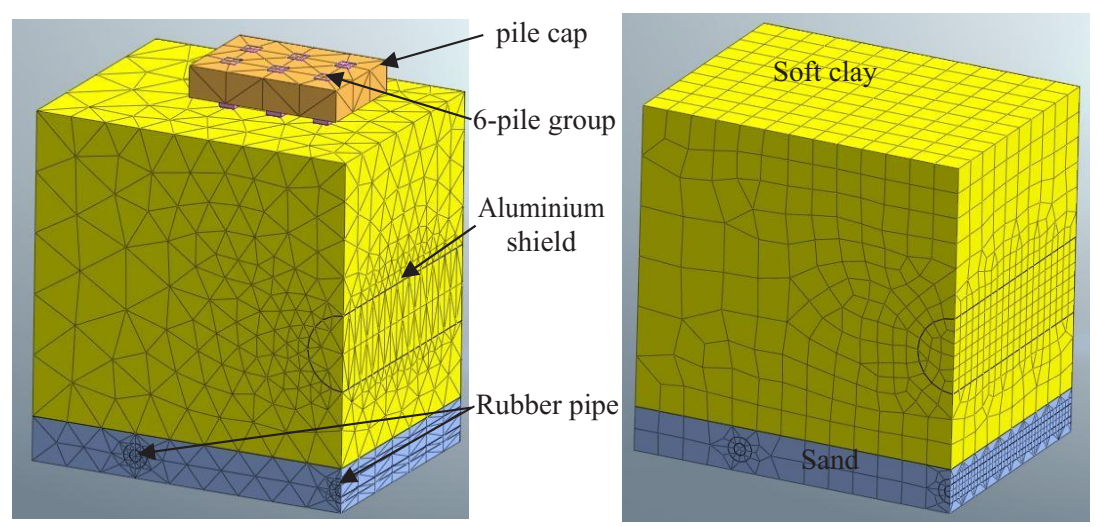

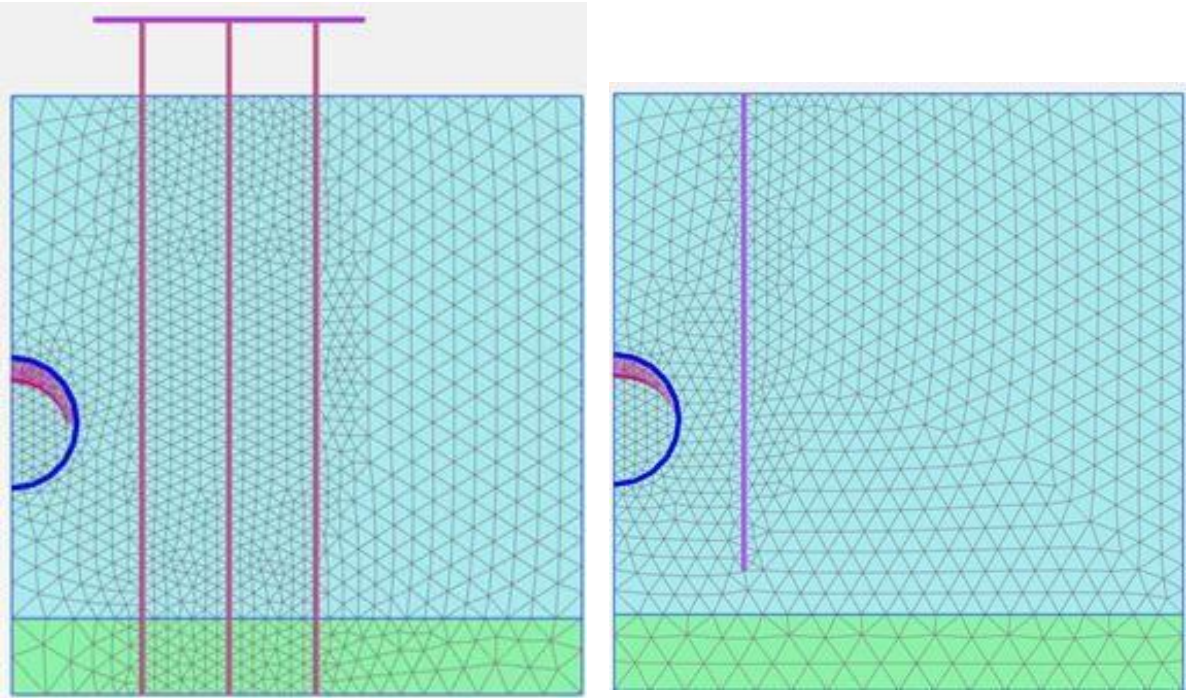

Fig. 2. 3D mesh in 6-pile group analysis (upper-left). 3D mesh in single pile group analysis (upper-right). 2D mesh in 6-pile group analysis (lower-left). 2D mesh in single pile group analysis (lower-right).

Figure 2 shows the 2D and 3D FE model for the problem. The tunnel is $6 \mathrm{~m}$ in diameter. The springline of the tunnel is $15 \mathrm{~m}$ from the ground level. Only half of the problem is modelled. Roller boundary condition is modelled at symmetrical line. The soil parameters are listed in Table 1 and 2. The pile is modelled by using 1-D beam in 3D model and embedded pile row in 2D model. The subsoil comprises of 24 meter thick Malaysian Kaolinite Clay overlays a $3.5 \mathrm{~m}$ thick dense Toyoura sand. The properties of the structural elements are shown in Table 3 to 6 . Case 1 is a single pile -tunnel interaction problem. The pile length is $22 \mathrm{~m}$, a floating pile. The pile is subjected to soil movement due to tunnelling process, $6.5 \%$ volume loss. nCase 2 is a 6-pile group - tunnel interaction problem. The pile length is $27.5 \mathrm{~m}$, an end bearing pile. The pile is directly sit on the base plate of strong box. $3 \%$ of volume loss was applied.

There are three processes in this problem. First, the pile is subjected to soil movement due to tunnelling in short period of time. Excess pore water pressure will be created in the active zone above the tunnel. The second process is the dissipation of the excess pore water pressure to it's original active pore water pressure. The third process is the seepage through the two perforated rubber pipe embedded in the sand layer. This will cause subsidence to the model. The second and third process are executed simultaneously. The first to the third process are modelled in 3D FE but only the first and second process are modelled in 2D model but this does not affect the direct comparison of the result of 2D and 3D because the subsidence only affect the axial load in the pile. Drained analysis is adopted in 2D FE which is a long- term analysis. Contraction mode similar to Gap method as adopted in Ong's (2009) thesis is replicated. The length of the mesh around the tunnel is set to 1 meter. The node of the mesh around the tunnel is inputted in both 2D and 3D model so that the coarseness around tunnel of the 2D and 3D FE remains the same.

Zero pressure head is applied around rubber pipe in stage 3 to allow seepage around rubber pipe. A 0.5 meter thick cylinder is created using 3D solid element. The outflow of water is controlled by the permeability of the thick cylinder. The thick cylinder has the same properties to the Toyoura sand except the permeability was set to $2 \mathrm{e}-7 \mathrm{~m} / \mathrm{s}$ to matched the long-term consolidation in centrifuge test.

The construction stages are : Stage 1 - initialization of ground stress. Stage 2 - install piles or pile group and reset displacement to zero. Stage 3 - apply contraction around tunnel and apply zero pressure head around rubber pipe. Stage 4 - Consolidation to dissipate excess pore water pressure to zero.

Figure 3 shows the comparison of soil movements in 3D FE and the centrifuge with $6.5 \%$ volume loss and Figure 5 shows the comparison for $3 \%$ volume loss. They are comparable well in short-term and long-term settlement. Figure 5 (left) shows the measured pore pressure in centrifuge during the setting up, tunnelling and dissipation of the excess pore pressure. The pore water pressure in the active zone above the tunnel in $3 \mathrm{D}$ model is shown in the right figure of Figure

6. An excess pore pressure of about $60 \mathrm{kPa}$ was generated during the tunnelling and it dissipates in about 80 days. The result is comparable to the measured one. Figure 4 shows the possible mode of bending of piles in tunnelling-pile and deep excavation -pile interaction problem. All geometries and properties adopted in 3D model is replicated in 2D model so that the closest comparison of the results can be made (Figure 7). The connection of the connection of pile and pile cap is set to be rigid. 


\subsection{Discussion of results in Case 1 - Interaction in between tunnelling and single pile}

Figure 8 shows the comparison of deflection, bending moment and axial load of measured data from centrifuge, 2D and $3 \mathrm{D} F E$ for the pile. The maximum deflection obtained from centrifuge test is $28 \mathrm{~mm}$. It happens at pile top and the deflection profile shows alike the deflection of a cantilever wall. Midas GTS NX 3D predicts a maximum 17 mm deflection but the maximum deflection happens at level at the springline of tunnel. Ong (2007) has back-analysed the problem using Plaxis 3D and he predicts $10 \mathrm{~mm}$ deflection. 2D FE predicts $63 \mathrm{~mm}$ deflection at pile top. It is understood that the embedded pile row was design for analysing pile row however it is tested in this exercise by specifying the spacing of pile of 3-diameter. It is not intended to compare the magnitude of the deflections of the various methods but attention should be drawn to the curvature exhibited by the embedded pile row element. Deflection of $10 \mathrm{~mm}$ or $17 \mathrm{~mm}$ or $28 \mathrm{~mm}$ practically are in the same range of deflection in term of the effect to the adjacent structures moreover it is very dependent on the shape of the contraction of the tunnel. The embedded pile row element tends to exhibit stiff behaviour or similar to short pile behaviour. Take note on the caution made by Sluis (2014) in Figure 1 of the embedded row element is only suitable for a pile length of greater than $8 \mathrm{D}$. Poulos has defined short pile as pile with length of less than 10D. If the embedded pile row is applied for a with pile length of greater than $10 \mathrm{D}$, it will then underestimate the induced bending moment because bending moment is a function of second derivative of curvature. It is expected that the bending moment will be underpredicted by embedded pile row element such as shown in Figure 8 (middle). The embedded pile row element also overpredict the axial load. Reminded that the subsidence was not modelled in 2D FE. If it was modelled, the number could have been higher.

Many pile-tunnel interaction problems have been analysed by various authors. In this problem, pile will move along with the soil surrounding it at similar amount. This behaviour is also observed in pile-deep excavation interaction problem (Poulos et. al, 2014). The deflection of pile is very similar to the soil movement surrounding the pile in centrifuge, 2D or 3D analysis, see Figure 9. Besides deflection and forces in the pile, settlement also comparable well with the measured data (Figure 10). Ong's 3D FE (2007) underestimated the settlement because subsidence was not modelled.

\subsection{Discussion of results in Case $\mathbf{2}$ - Interaction in between tunnelling and pile group}

Figure 11 shows the comparison of deflection, bending moment and axial force in the pile of centrifuge results, 2D and 3D FE. Generally, the 2D and 3D FE predict greater deflection than the centrifuge result. However, Figure 12 (left) shows that pile does not move together with the surrounding soil or it can be interpreted as the Kaolinite clay flows around the piles during the tunnelling. This is contradictory to the behaviour in single pile where the volume loss of the tunnel is even larger, $6.5 \%$ and hence the centrifuge result is suspicious.

If the pile is sit directly onto the base place of the strong box, then the piles are restricted from moving at vertical direction and all the load will be transferred to the pile toe such as a column in a structure where the maximum axial load is at the pile toe and the maximum axial load will not happen at some distance away above the pile too, alike axial load in a downdraged pile. Again, embedded pile row exhibit stiff behaviour. The little bending near the pile head was due to the fixed-head condition at pile head. The little decrease of axial force in 2D FE was due to the stiffness of spring at pile base has to be explicitly assigned to a high value to model it as end bearing pile. The end node of the embedded pile row is not connected to the mesh.

Table 1 Properties for Kaolin Table 2 Properties for sand Table 3 Properties for rubber

\begin{tabular}{|l|c|}
\hline Modified Cam Clay Model for & an Kaolin \\
\hline Parameter & Valu \\
\hline Saturated unit weight, $\gamma_{w}$ & 16.4 \\
\hline Permeability in all directions, $\mathrm{K}$ & $2 \mathrm{e}-8$ \\
\hline Over consolidated ratio, OCR & 1 \\
\hline Slope of consolidation line, $\lambda$ & 0.24 \\
\hline Slope of over-consolidation line, & $\mathbf{0 . 0 5}$ \\
\hline Initial void ration, $\mathrm{e}_{\mathrm{o}}$ & $\mathbf{2}$ \\
\hline Lateral earth pressure & 1 \\
\hline Poisson's ratio & 0 \\
\hline
\end{tabular}

Table 4 Properties for pile cap

\begin{tabular}{|l|c|}
\hline Elastic model for pile cap \\
\hline Parameter & Value \\
\hline Unit weight, $\gamma$ & $24 \mathrm{kN} / \mathrm{m}^{3}$ \\
\hline Young's modulus, E & $200 \mathrm{GPa}$ \\
\hline Poisson's ratio & 0.2 \\
\hline
\end{tabular}

Table 5 Properties for pile

\begin{tabular}{|l|c|}
\hline Mohr Coulomb model for & $\begin{array}{c}\text { Toyoura } \\
\text { Value }\end{array}$ \\
\hline Parameter & 18 \\
\hline Saturated unit weight, $\gamma_{\mathrm{w}}$ & $1 \mathrm{e}-5$ \\
\hline Permeability in all & 167.5 \\
\hline Young's modulus, E & 3 \\
\hline Effective friction angle, $\phi^{\prime}$ & 0 \\
\hline Poisson's ratio & 8 \\
\hline Relative density, ID & \\
\hline
\end{tabular}

\begin{tabular}{|l|r|}
\hline \multicolumn{2}{|l|}{ Elastic model for rubber pipe } \\
\hline Parameter & Val \\
\hline Unit weight, $\gamma$ & $15 \mathrm{kN} / \mathrm{m}^{3}$ \\
\hline Width & 70 \\
\hline Young's modulus, & $100 \mathrm{MPa}$ \\
\hline Poisson's ratio & 0.4 \\
\hline
\end{tabular}

\begin{tabular}{|l|c|}
\hline Elastic model for pile \\
\hline Parameter & Value \\
\hline Unit weight, $\gamma$ & $24 \mathrm{kN} / \mathrm{m}^{3}$ \\
\hline Pile width & $1.26 \mathrm{~m} \mathrm{x}$ \\
\hline Young's modulus, & $28.3 \mathrm{GPa}$ \\
\hline Poisson's ratio & 0.2 \\
\hline
\end{tabular}

Table 6 Properties for shield

\begin{tabular}{|l|c|}
\hline \multicolumn{2}{|l|}{ Elastic model for aluminium tunnel } \\
\hline Parameter & Value \\
\hline Unit weight, $\gamma$ & 16 \\
\hline Width & 70 \\
\hline Young's modulus, & 59 \\
\hline Poisson's ratio & 0.2 \\
\hline
\end{tabular}



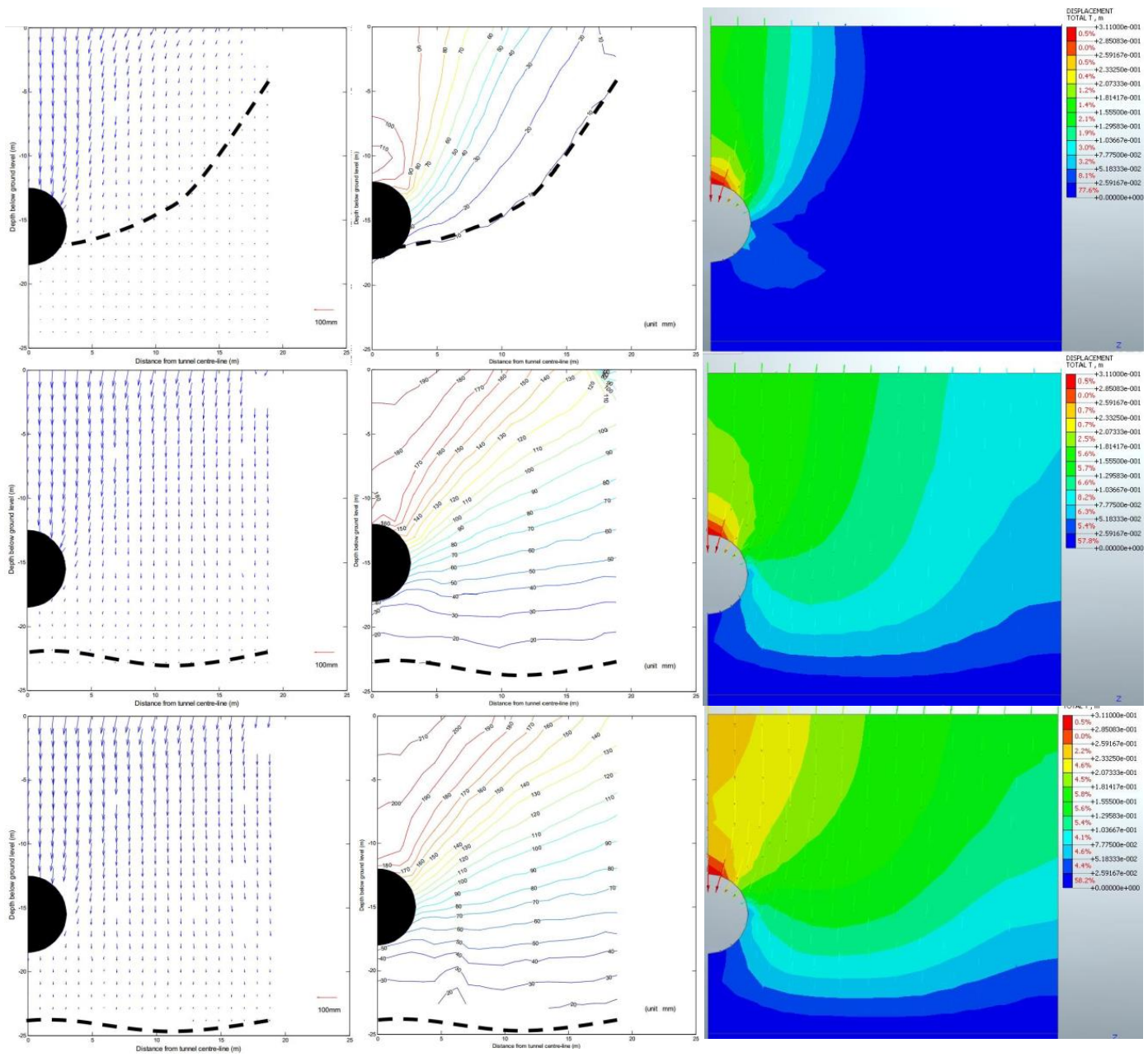

Fig. 3. Matching the soil movement in 3D FE to centrifuge results for 0.2 days (top row), 40 days (middle row) and 80 days (bottom row) for $6.5 \%$ volume loss (after Ong, 2009). The left and the middle are the results from centrifuge tests. The right is the result from 3D FE.

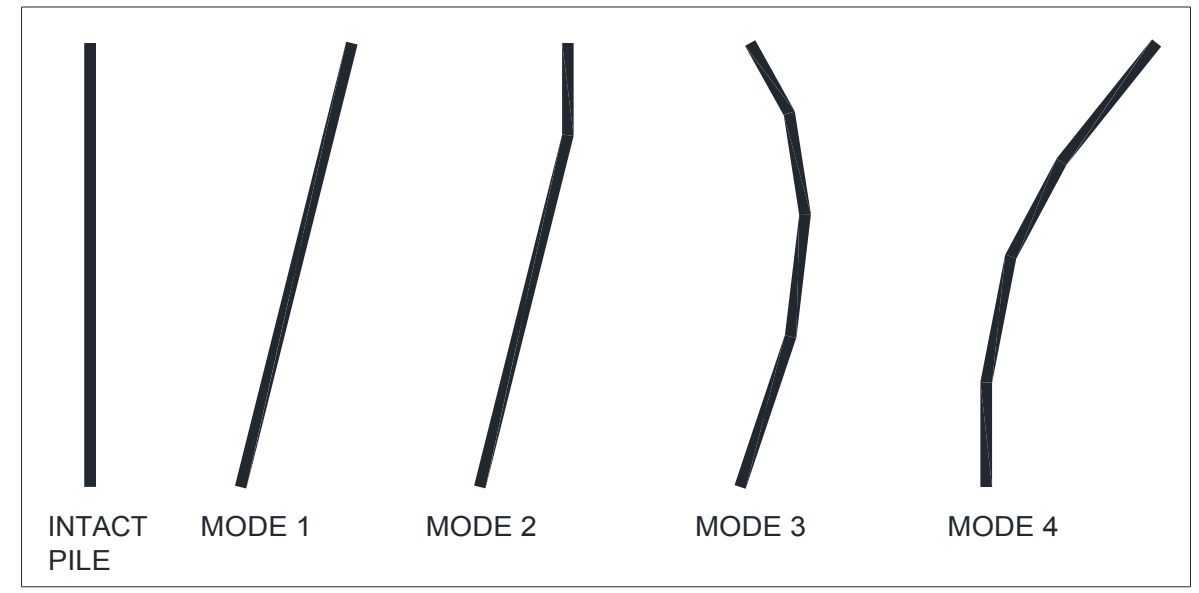

Fig. 4. Mode of bending in pile in tunnelling-pile interaction problem 

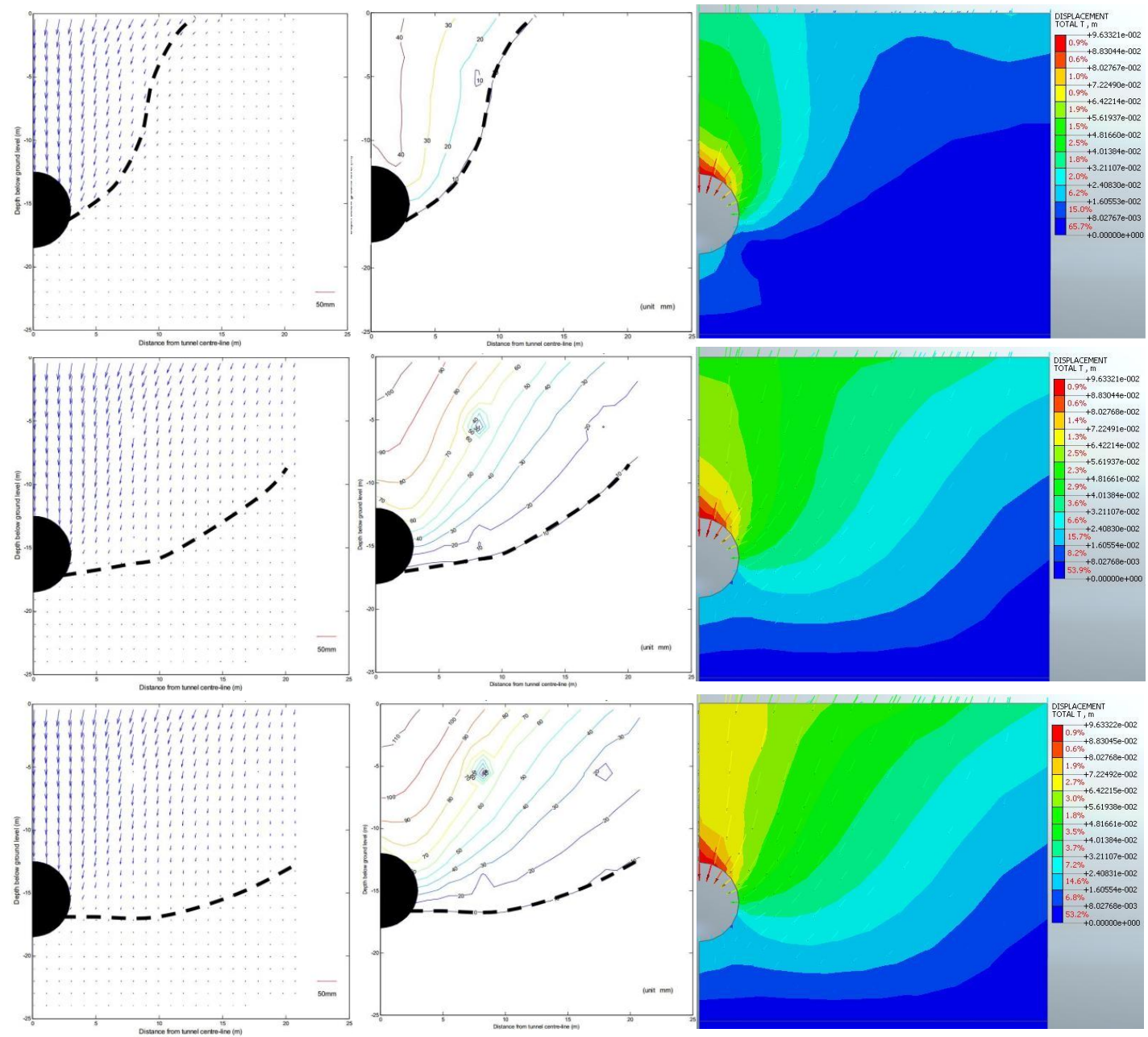

Fig. 5. Matching the soil movement in 3D FE to centrifuge results for 0.2 days (top row), 40 days (middle row) and 80 days (bottom row) for $3 \%$ volume loss (after Ong, 2009). The left and the middle are the results from centrifuge tests. The right is the result from 3D FE.
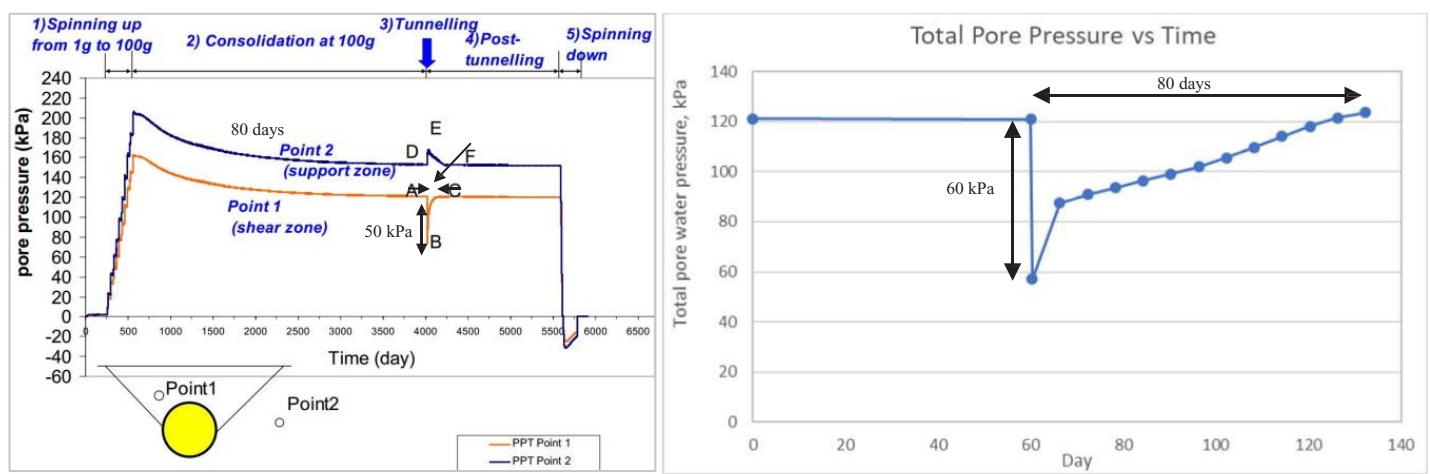

Fig. 6. Matching pore water pressure in 3D FE and the centrifuge result (modified from Ong, 2009) 


\section{ICCOEE 2018}
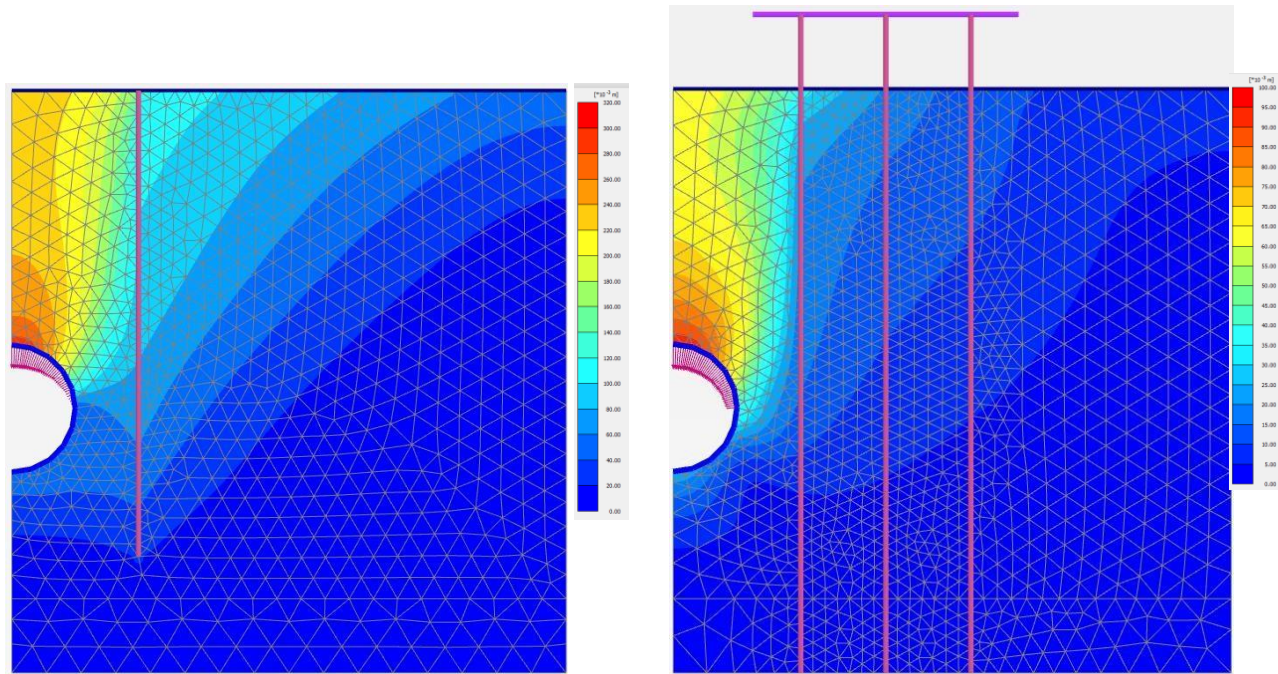

Fig. 7. 2D FE mesh for single pile and pile group analysis
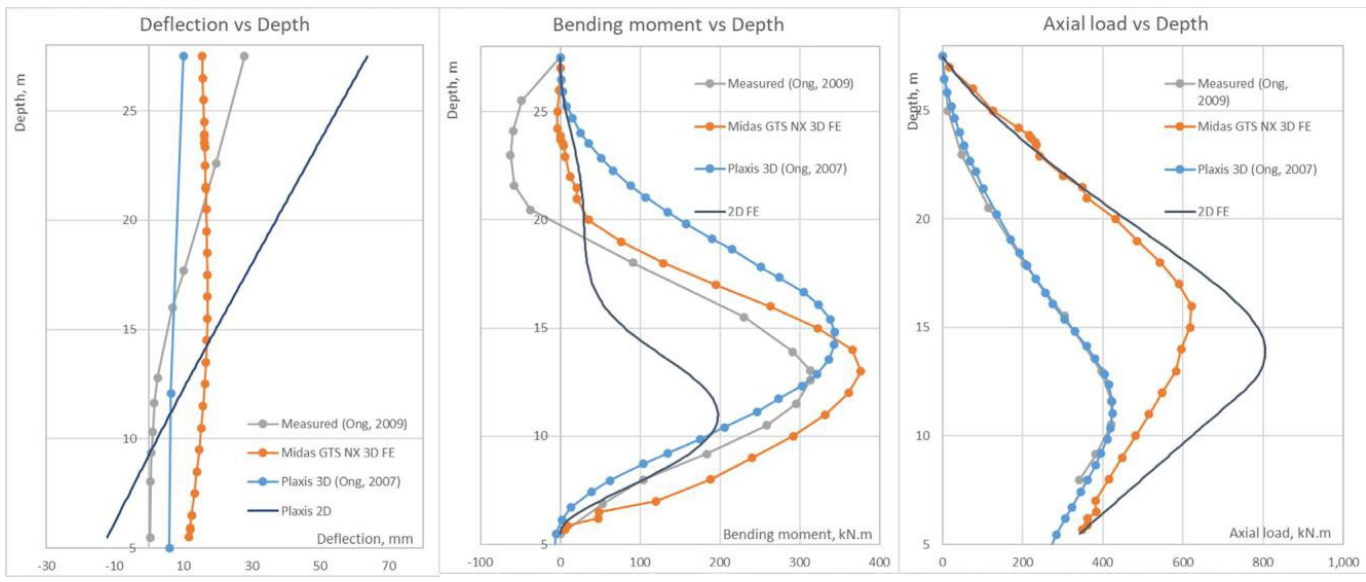

Fig. 8. Comparison of deflection of pile, bending moment and axial force in centrifuge, 2D FE and 3D FE for $6.5 \%$ volume loss
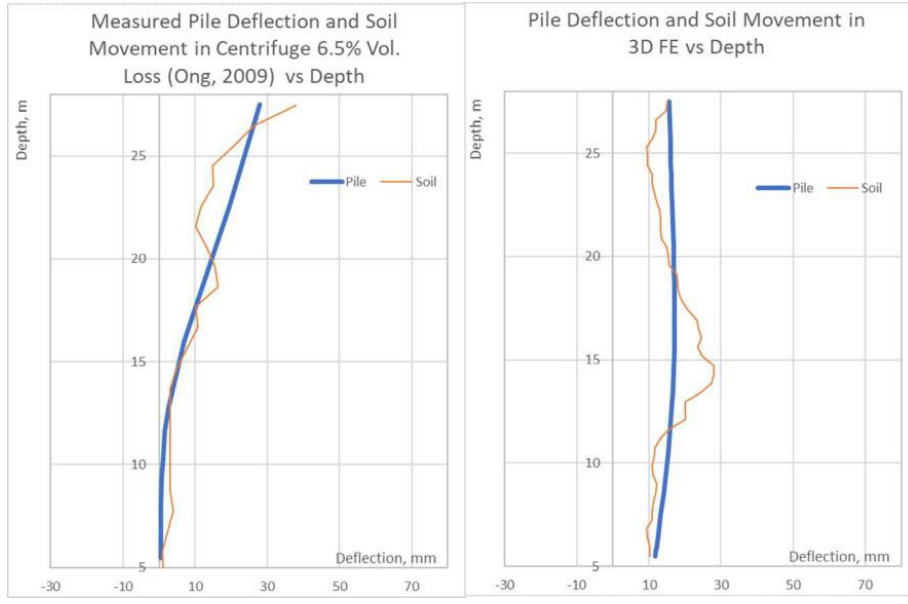

Pile Deflection and Soil Movement in 2D FE vs Depth

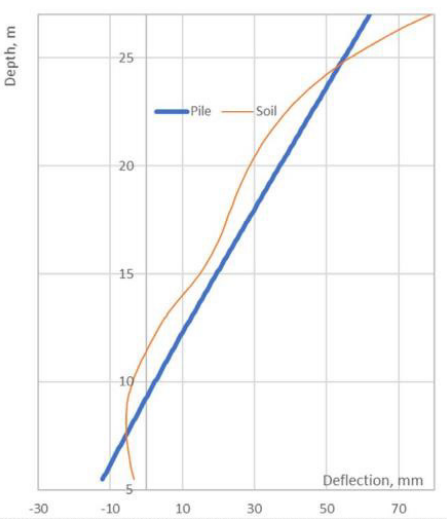

Fig. 9. Comparison of soil movement and deflection of pile for $6.5 \%$ volume loss 

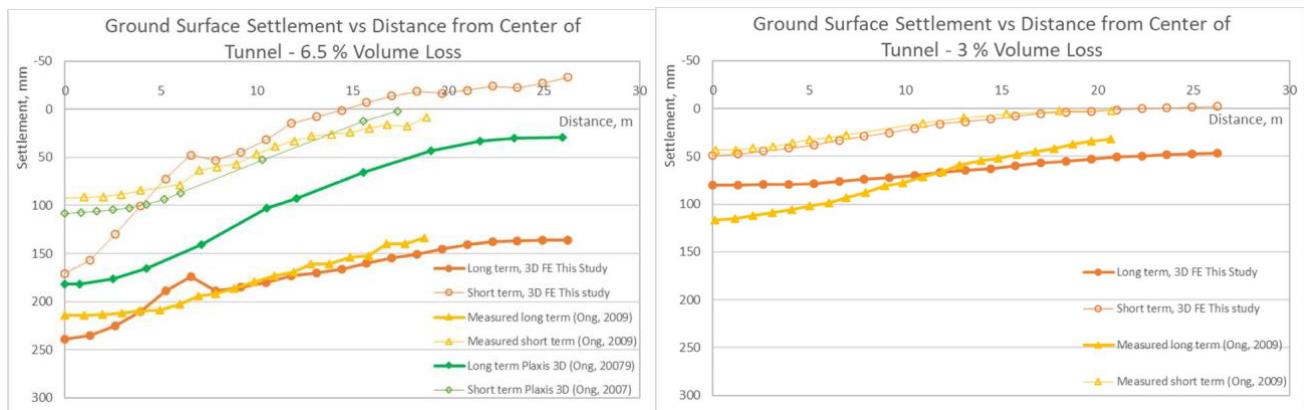

Fig. 10. Comparison of settlement in centrifuge, 3D FE using Plaxis 3D and 3D FE using Midas GTS NX for 6.5\% volume loss
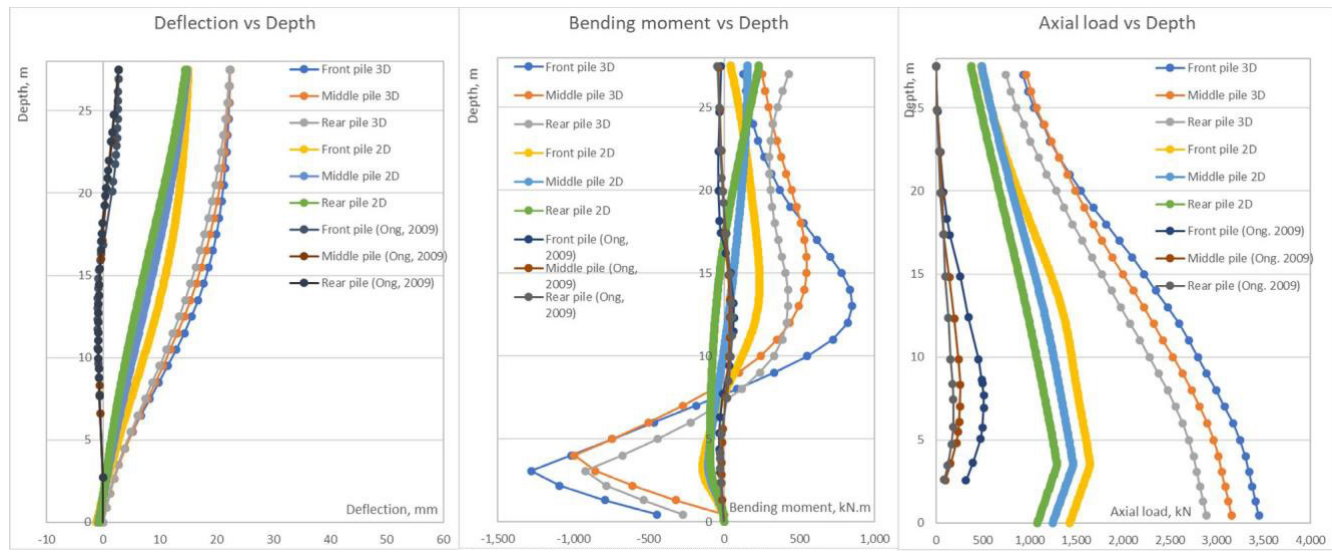

Fig. 11. Comparison of deflection of pile, bending moment and axial force in centrifuge, 2D FE and 3D FE for 3\% volume loss
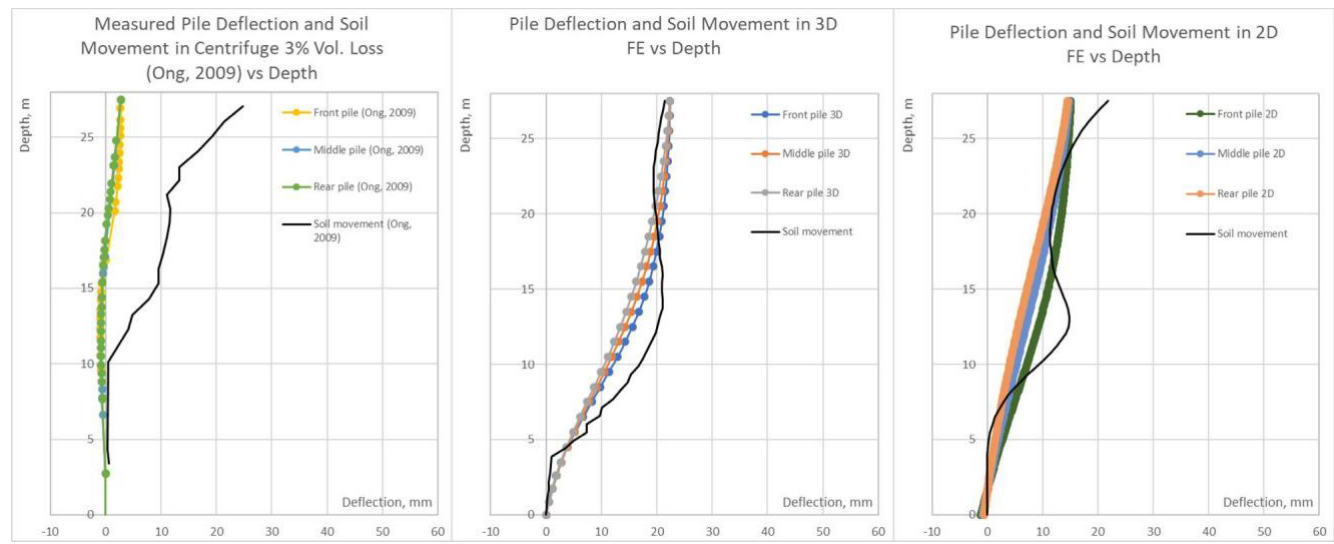

Fig. 12. Comparison of soil movement and deflection of pile for $3 \%$ volume loss

\section{Effect of deep excavation to adjacent piles}

This is a 2-basement excavation problem with the MRT pile groups already constructed prior to the proposed excavation, using top-down construction method. The MRT piers are supported by $3 \times 1500 \mathrm{~mm}$ diameter-pile group and the escalator structures are supported by $3 \times 600 \mathrm{~mm}$ diameter-single piles. The typical cross sections are shown in Figure 13 and 14 . A 3D-FE was carried out to model the effect of the excavation to the adjacent piles. The 3D model comprises of 260,000 tetrahedron and hexahedron elements. The bored piles are modelled by 1-D beam element, see Figure 15. Pile-soil interface is modelled to connect the beam element to the soil. The input parameters of the pile-soil interface element are the ultimate shaft friction and the stiffness of the spring, aka load transfer method. 


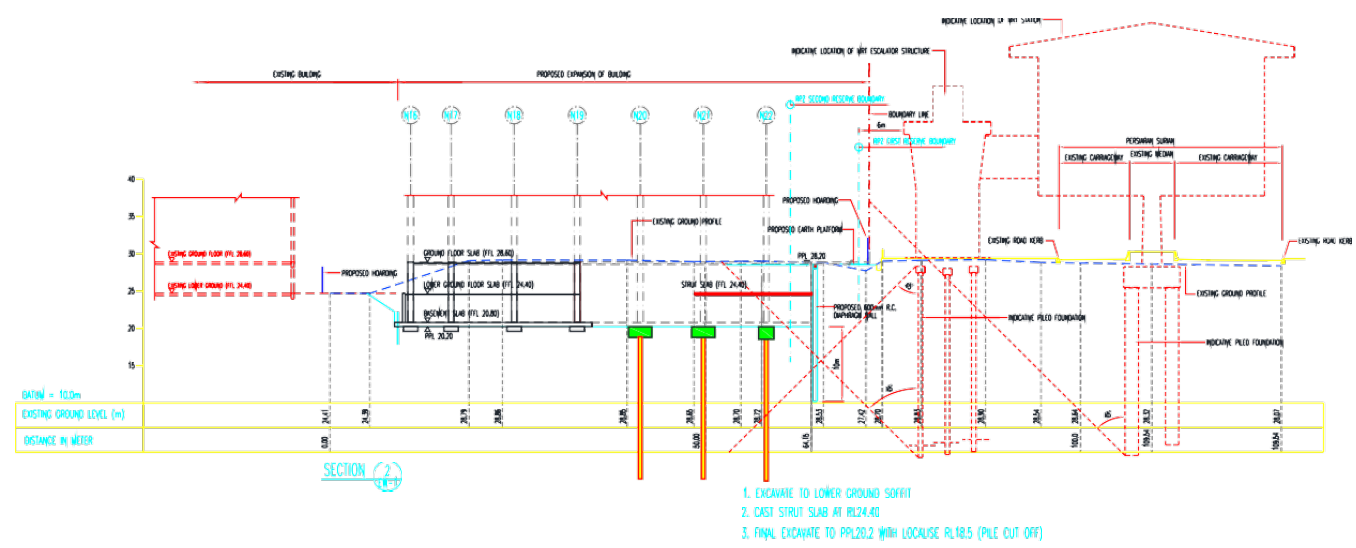

Fig. 13. Cross section of MRT piles and 2-basement excavation

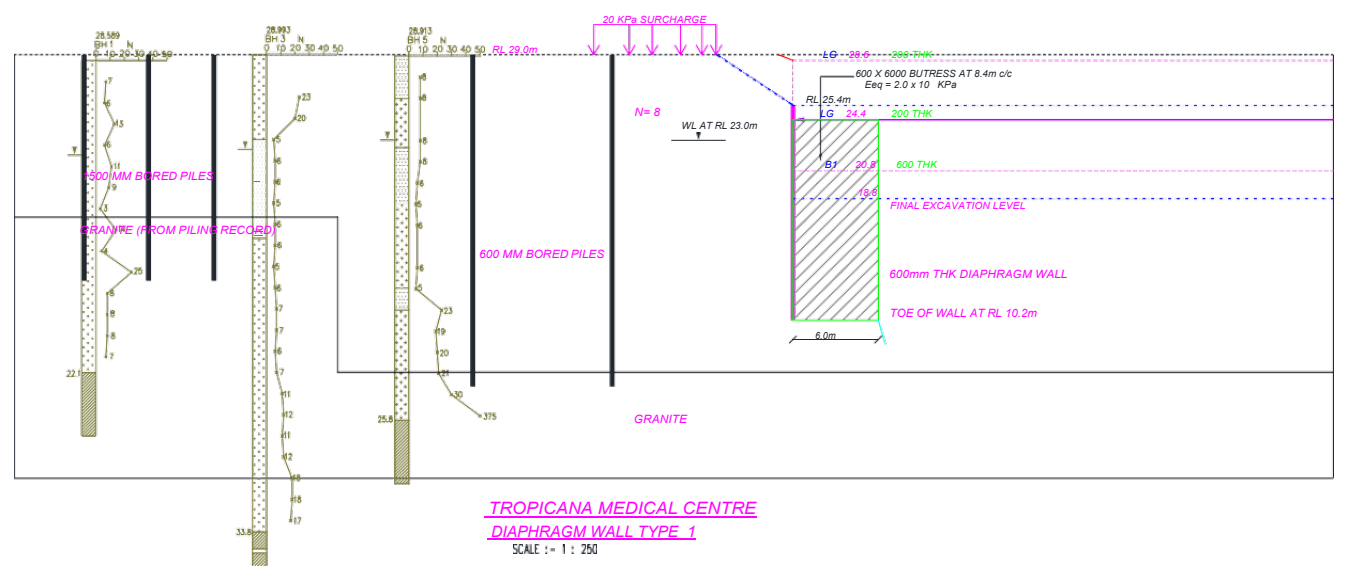

Fig. 14. Subsoil conditions

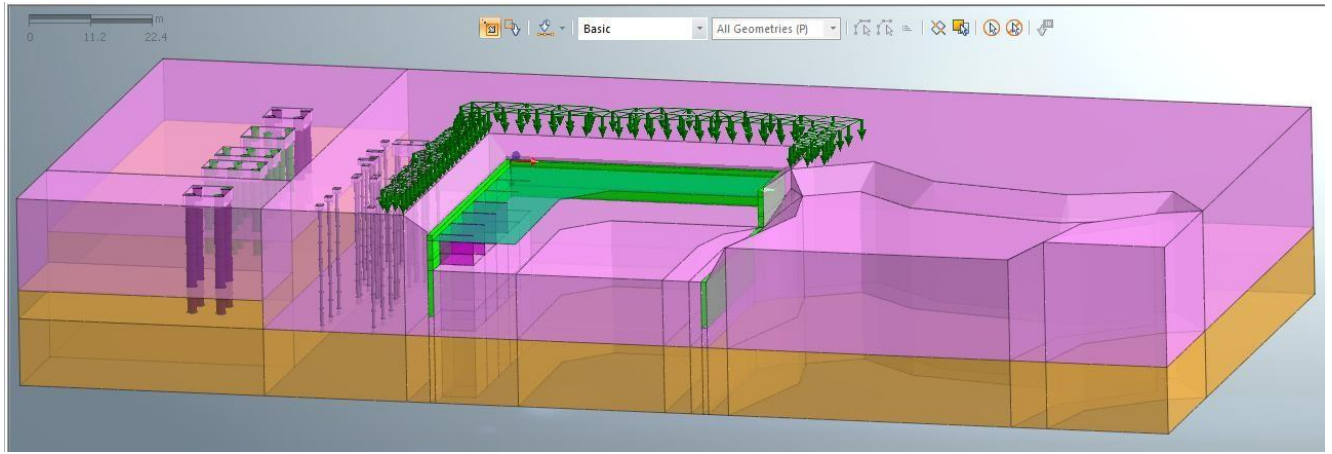

Fig. 15. 3D model of Midas GTS NX 2017 (Front view)

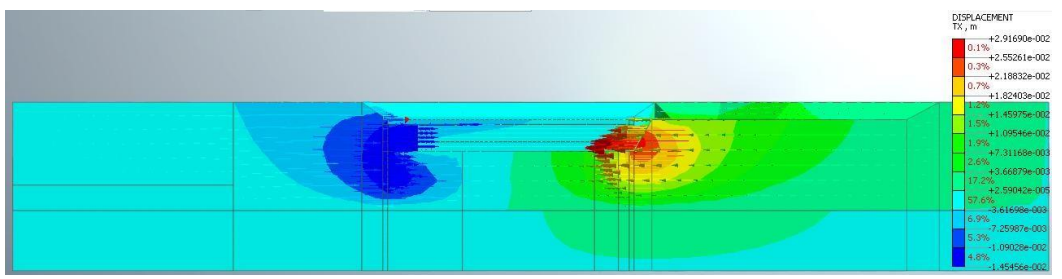

Fig. 16. Deflection in x-direction when excavate to RL18.8m in Midas GTS NX 2017 (Front view) 
Table 7. Properties of soils and structure in Midas GTS NX and Plaxis

\begin{tabular}{|c|c|c|c|c|c|c|c|c|c|c|c|}
\hline \multicolumn{10}{|c|}{ MIDAS GTS NX 2017} & \multicolumn{2}{|c|}{ PLAXIS } \\
\hline $\mathrm{RL}, \mathrm{m}$ & Description & Soil model & $\mathrm{c}^{\prime}$ & $\phi '$ & Ko & $\mathrm{E}_{\text {oedref }}$ & $\mathrm{E}_{50 \mathrm{ref}}$ & $\mathrm{v}$ & $\mathrm{k}$ & $\mathrm{E}_{\text {oedref }}$ & $\mathrm{E}_{50 \mathrm{ref}}$ \\
\hline $\mathrm{m}$ & - & - & $\mathrm{kPa}$ & $\circ$ & - & $\mathrm{MPa}$ & $\mathrm{MPa}$ & & $\mathrm{m} / \mathrm{s}$ & $\mathrm{MPa}$ & $\mathrm{MPa}$ \\
\hline 29.0 to 6.5 & SPT N 8 sandy silt & Modified Mohr Coulomb & 5 & 28 & 0.53 & 8 & 20 & 0.2 & $1 \mathrm{e}-7$ & $16^{* * *}$ & $48 * *$ \\
\hline 6.5 to -6.0 & Granite & Elastic & - & - & 1.00 & $8 \mathrm{e} 3^{*}$ & - & 0.2 & $1 e-9$ & - & - \\
\hline- & Concrete for slab & Elastic & - & - & 1.00 & $26 \mathrm{e}^{*}$ & - & 0.2 & $1 \mathrm{e}-9$ & - & - \\
\hline- & Concrete for pile & Elastic & - & - & 1.00 & $27 \mathrm{e} 6^{*}$ & - & 0.2 & $1 \mathrm{e}-9$ & - & - \\
\hline- & $600 \mathrm{~mm}$ Buttress & Elastic & - & - & 1.00 & $15 \mathrm{e}^{*}$ & - & 0.2 & $1 \mathrm{e}-9$ & - & - \\
\hline
\end{tabular}

*Esecant, ${ }^{* *}$ Hardening soil model

Table 8. Properties of bored piles

\begin{tabular}{|c|c|c|c|c|c|c|c|c|c|c|}
\hline \multicolumn{6}{|c|}{$600 \mathrm{~mm}$ diameter bored pile } & \multicolumn{5}{|c|}{$1500 \mathrm{~mm}$ diameter bored pile } \\
\hline $\begin{array}{l}\mathrm{RL}, \\
\mathrm{m}\end{array}$ & $\begin{array}{l}\text { Descriptio } \\
\mathrm{n}\end{array}$ & $\begin{array}{l}\text { Ult. } \\
\text { Shaft } \\
\text { Friction }\end{array}$ & $\begin{array}{l}\text { Shear } \\
\text { modulus }\end{array}$ & $\begin{array}{l}\text { Ultimate } \\
\text { base } \\
\text { resistance }\end{array}$ & $\begin{array}{l}\text { Base } \\
\text { stiffness }\end{array}$ & $\begin{array}{l}\text { Ult. } \\
\text { Shaft } \\
\text { Friction }\end{array}$ & $\begin{array}{l}\text { Shear } \\
\text { modulus }\end{array}$ & $\begin{array}{l}\text { Ultimate } \\
\text { base } \\
\text { resistance }\end{array}$ & $\begin{array}{l}\text { Base } \\
\text { stiffness }\end{array}$ & $\begin{array}{l}\text { Ult. Shaft } \\
\text { Friction }\end{array}$ \\
\hline $\mathrm{m}$ & - & $\mathrm{kPa}$ & $\mathrm{kPa} / \mathrm{m}$ & $\mathrm{kPa}$ & $\mathrm{kN} / \mathrm{m}$ & $\mathrm{kPa}$ & $\mathrm{kPa} / \mathrm{m}$ & $\mathrm{kPa}$ & $\mathrm{kN} / \mathrm{m}$ & $\mathrm{kPa}$ \\
\hline $\begin{array}{l}29.0 \\
\text { to } 6.5 \\
\end{array}$ & $\begin{array}{l}\text { SPT N } 8 \\
\text { sandy silt }\end{array}$ & 48 & 10666 & - & - & 48 & 10666 & - & - & 48 \\
\hline $\begin{array}{l}6.5 \text { to } \\
-6.0\end{array}$ & Granite & 600 & 100000 & 12000 & 282780 & 600 & 100000 & 12000 & 706950 & 600 \\
\hline
\end{tabular}

Fully coupled seepage stress analysis was carried in Midas GTS NX while steady state ground water plastic analysis was adopted in $2 \mathrm{D}$ analysis.

There are nine construction stages in Midas GTS NX including the construction of slab at RL20.8m and RL28.6m, the construction of reinforced concrete wall above the diaphragm wall and 30 years of consolidation. The simplified construction stages are;

- Generalize ground stress at RL29m

- Construct diaphragm wall, bored piles, pile cap, buttress wall and reset displacement to zero

- Excavate to RL24.4m

- Construct $200 \mathrm{~mm}$ thick slab at RL24.4m

- Excavate to RL18.8m

\subsection{Modelling of diaphragm wall and buttress wall and pore pressure in 2D and 3D}

The two-basement excavation is supported by $600 \mathrm{~mm}$ thick diaphragm wall. Buttress wall was proposed to limit the deflection of the diaphragm wall to $15 \mathrm{~mm}$ as the requirement of MRT Corporation, the local authority that oversee the construction adjacent to MRT train. The diaphragm wall and buttress wall were modelled by 2D shell element in Midas GTS NX 3D. It is not possible to model the buttress wall which is $3 \mathrm{D}$ in nature in 2D FE software. But it is adequate to model the buttress wall by increase the stiffness of the soil within the buttress wall to give similar magnitude of deflection of diaphragm wall in 3D FE to facilitate the study of the effect of excavation to the piles. The Young's modulus of soil was increased from $28 \mathrm{MPa}$ to $72 \mathrm{MPa}$ to give a deflection of diaphragm wall of $15 \mathrm{~mm}$, see Figure $16 \& 17$ for the horizontal movement of 2D and $3 \mathrm{D}$ FE. Comparison of deflection and forces in diaphragm wall in $2 \mathrm{D}$ and $3 \mathrm{D}$ FE is shown in Figure 18. It is not the intended to match the forces in diaphragm wall of 2D and 3D. It is also necessary to match the pore water pressure in $2 \mathrm{D}$ and 3D. Pore water pressure obtained from 3D FE is inputted into 2D FE. Properties of soils and structural elements are give in Table 7 and the properties of pile-soil interface are given in Table 8 .

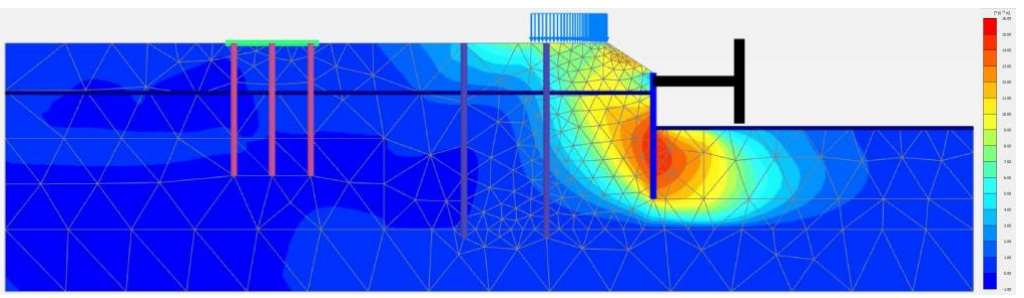

Fig. 17. Deflection in $\mathrm{x}$-direction when excavate to RL18.8m in 2D FE (Front view) 


\subsection{Comparison of deflection and forces in bored piles in 2D and 3D}

Comparison of deflection and forces of $600 \mathrm{~mm}$ diameter bored pile of 2D and 3D is shown in Figure 19. The deflection of pile showed stiff behaviour in deflection and it is similar to short pile behaviour and therefore the embedded pile row element underestimates the bending moment. Similar behaviour is repeated in $1500 \mathrm{~mm}$ diameter bored piles (Figure 20). The bending moment in 2D FE is overestimated if the pile cap is modelled as plate element and fixed-head condition is assumed. A lower bending moment of pile top in 3D FE shows some degree of release of rotational stiffness in pile cap. Axial load in 2D FE is again overestimated.
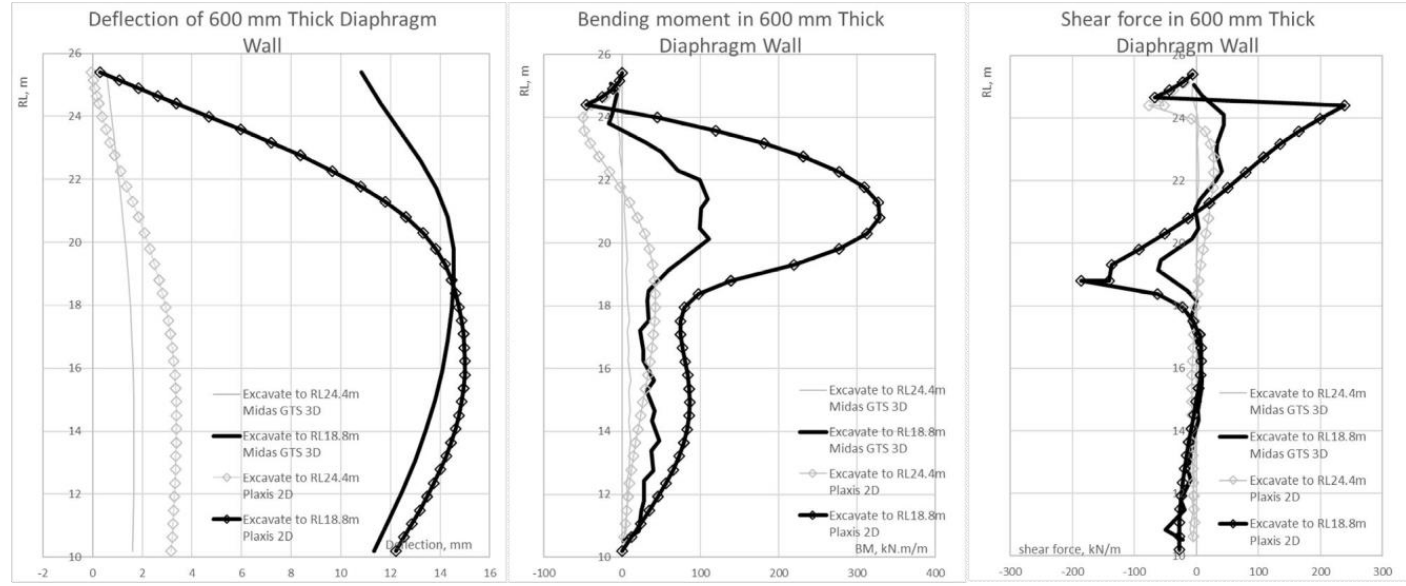

Fig. 18. Deflection, bending moment and shear forces in $600 \mathrm{~mm}$ diaphragm wall, $2 \mathrm{D}$ and 3D
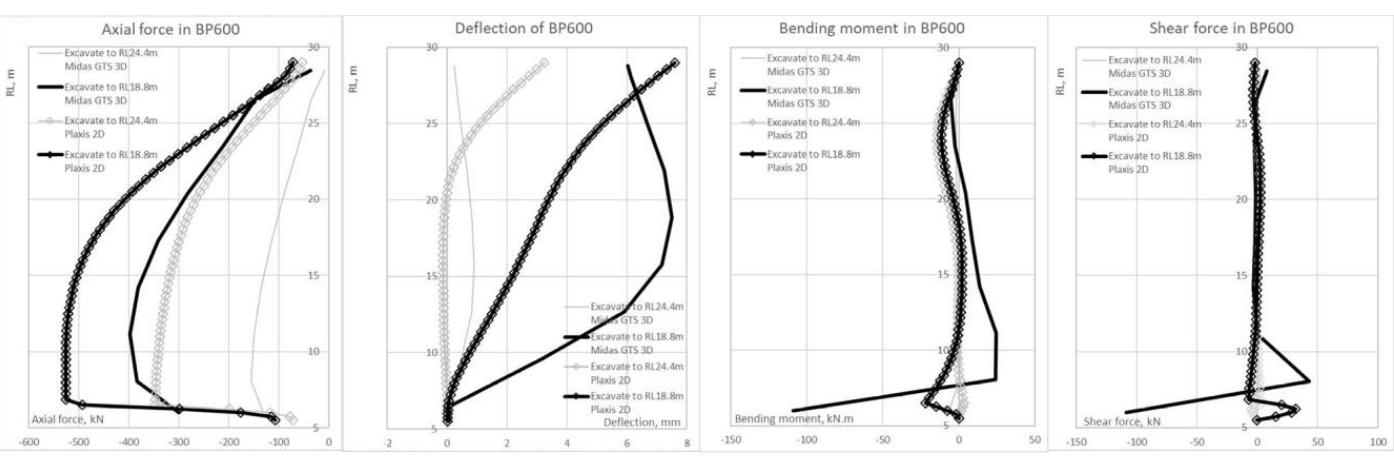

Fig. 19. Axial force, deflection, bending moment and shear forces in $600 \mathrm{~mm}$ bored pile, 2D and 3D
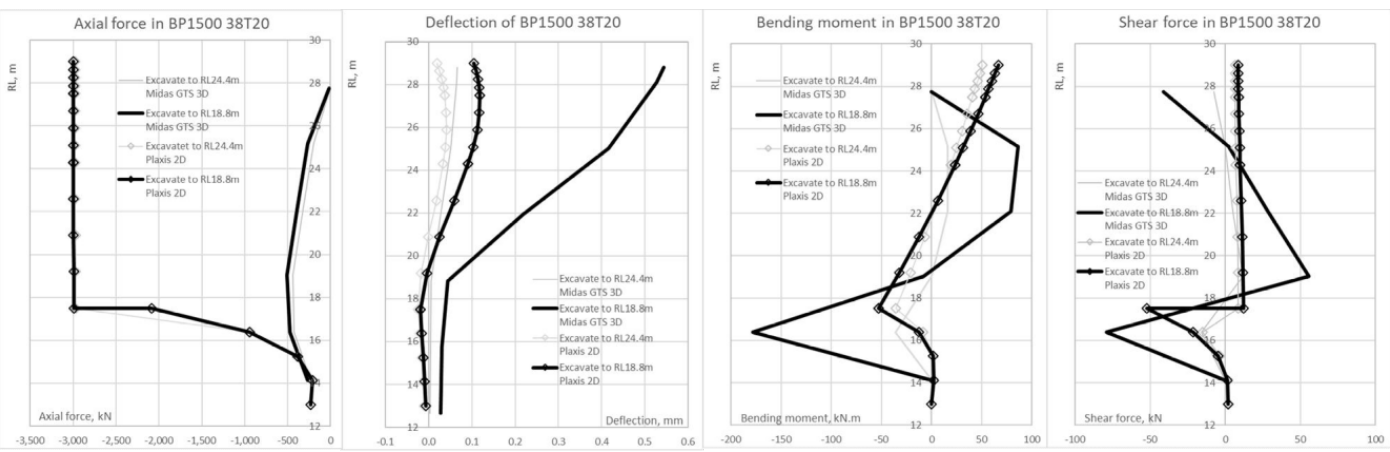

Fig. 20. Axial force, deflection, bending moment and shear forces in $1500 \mathrm{~mm}$ bored pile, 2D and 3D 


\section{Successful use of embedded pile row}

The performance of the embedded pile row element was tested in quay-wall structure, piled embankment and stability of piled slope and the results are encouraging. However, in all these cases, by nature of the configuration of the problem or loading conditions, the pile tend to deflect in such a way very similar to short piles such as mode 1 (free head) and mode 2 (fixed-head) in Figure 4 and therefore the results are comparable to the 3D FE. However, if a long pile is subjected to soil movement well below the ground surface such as in tunnel problems or a long pile is subjected to soil movement due to deep excavation, refer to mode 3 and mode 4 in Figure 4 , then the embedded pile row is not suitable because it underestimates the bending moment.

\section{Conclusions}

Back-analysis of pile-tunnelling and pile-deep excavation problems are shown in this paper. In both cases, external load is applied onto pile below pile head in the form of soil movement. In these situations, bending moment (and therefore shear force) in pile tend to be underestimated if embedded pile row is deployed to model a pile in 2D FE due to stiff behaviour shown by embedded pile row element. The magnitude of deflection can be predicted correctly. But if the pile is loaded at or near the pile head such as pile supported quay wall or piled embankment, the embedded pile row is useful and it saves a lot of computation time.

\section{References}

1. C.W. Ong, C.F. Leung, K.Y. Yong and Y.K. Chow, "Performance of pile due to tunnelling-induced soil movements", Underground Space - The 4th Dimension of Metropolises, Proceeding of the 33rg ITA-AITES World Tunnel Congress, Prague, Czech Republic, 619-624, Taylor \& Francis Group, 5-10 May 2007

2. C. W. Ong, “Centrifuge model study of tunnel-soil-pile interaction in soft clay”, Ph.D Thesis, National University of Singapore, 2009

3. J.J.M. Sluis, F. Bessling and P.H.H. Stuurwold, "Modelling of a pile row in a 2D plane strain FE-analysis," Numerical Methods in Geotechnical Engineering - Hicks, Brinkgreve \& Rohe (Eds), Taylor \& Francis Group, London, 978-1138-00146-6, pp. 277-282, 2014.

4. M. Tomlinson and J. Woodward "Pile design and construction practice, 6th edition", CRC Press, page 329, 2014

5. B.v.d. Kwaak. "Modelling of dynamic pile behaviour during an earthquake using Plaxis 2D : Embedded beam (rows)", Master thesis, Delft University of Technology, 2015

6. Plaxis2D 2017 Reference Manual

7. H.G. Poulos. "Effect of urban construction on existing pile foundation", www.iqpc.com/media/8068/6449.pdf, accessed on 18th April 2018 